\title{
Twenty-Five Years of Physical Punishment Research: What Have We Learned?*
}

\author{
Joan E. Durrant ${ }^{1}$ and Ron Ensom ${ }^{2}$ \\ ${ }^{1}$ Department of Community Health Sciences, Max Rady College of Medicine, University of Manitoba, Winnipeg, Canada \\ ${ }^{2}$ Ensom \& Associates; and Children's Hospital of Eastern Ontario, Canada
}

\begin{abstract}
Over the past quarter century, research on physical punishment has proliferated. Almost without exception, these studies have identified physical punishment as a risk factor in children's behavioral, emotional, cognitive and brain development. At the same time, the United Nations has established that physical punishment constitutes a breach of children's basic human rights to protection and dignity. Together, research findings and human rights standards have propelled profound global change. To date, 51 countries have prohibited all physical punishment of children. In this article, we review the literature on physical punishment within its historical context, and provide recommendations for health professionals working with families.
\end{abstract}

Key Words: Physical punishment; Corporal punishment; Child abuse; Child development; Children's rights.

Received: October 1, 2016 / Revision: November 11, 2016 / Accepted: November 12, 2016

Address for correspondence: Joan E. Durrant, Department of Community Health Sciences, Max Rady College of Medicine, 35 Chancellors Circle, University of Manitoba, Winnipeg MB R3T 2N2, Canada

Tel: +1-204-474-8060, Fax: +1-204-789-3905, E-mail: Joan.Durrant@umanitoba.ca

The past quarter-century has witnessed a global shift in knowledge and thinking about physical punishment of children. In 1990, empirical evidence of the association between physical punishment and negative developmental outcomes was just beginning to accumulate, and the Convention on the Rights of the Child (CRC) had just been adopted by the General Assembly of the United Nations. Only four countries had prohibited physical punishment in all settings.

By 2000, research was proliferating, the CRC had been ratified by 191 countries; 11 countries had prohibited physical punishment of children in all settings, including the home; and the Republic of Korea had addressed child abuse in its protection laws. Today, research showing the risks associated with physical punishment is robust, the CRC has been integrated into the legal and policy frameworks of many nations, 51 countries have enacted prohibitions against physical punishment of children and 55 more have committed to doing so. ${ }^{1)}$ These three forces-research, the CRC and law reform-have altered the landscape of physical punishment worldwide.

The growing weight of research and recognition of children's

*This paper is an update of Durrant JE, Ensom R. Physical punishment of children: lessons from 20 years of research. CMAJ 2012;184:1373-1377.

This is an Open Access article distributed under the terms of the Creative Commons Attribution Non-Commercial License (http://creativecommons.org/licenses/by-nc/3.0) which permits unrestricted non-commercial use, distribution, and reproduction in any medium, provided the original work is properly cited. rights have brought us to a historical point. Mental and physical health professionals who are familiar with the research can now confidently encourage parents to adopt constructive approaches to discipline as they do when guiding other aspects of children's healthy development. In doing so, they strengthen child well-being and parent-child relationships at the population level. Here, we present an analysis of research on physical punishment spanning the past 25 years to assist health professionals in this important role.

\section{THE EARLY YEARS: IDENTIFYING PATTERNS}

Just one generation ago, physical punishment of children was generally viewed as an appropriate method of eliciting behavioral compliance from children and as conceptually distinct from physical abuse. However, this perspective began to change as studies found links between 'normative' physical punishment and child aggression, delinquency and spousal assault in later life. Some of these studies were based on large representative samples from the United States; ${ }^{2)}$ some studies controlled for potential confounders, such as parental stress ${ }^{3)}$ and socioeconomic status; ${ }^{4}$ and some examined the potential of parental reasoning to moderate the association between physical punishment and child aggression. ${ }^{5}$ Virtually without exception, these studies found that physical 
punishment was associated with higher levels of aggression against parents, siblings, peers and spouses.

But were physical punishment and child aggression statistically associated because more aggressive children elicit higher levels of physical punishment? While this can be the case, ${ }^{6}$ research was beginning to show that physical punishment also elicits aggression. Experimental studies had long ago revealed that pain elicits reflexive aggression. ${ }^{7}$ In an early modeling study, ${ }^{8)}$ boys in grade one who watched a one-minute video of a boy being yelled at, shaken and spanked with a paddle for misbehaving, showed more aggression while playing with dolls than boys who watched a one-minute video of non-violent responses to misbehavior. In a treatment study, Forgatch showed that a reduction in harsh discipline used by parents of boys at risk for antisocial behavior was followed by significant reductions in their children's aggression. ${ }^{9}$ ' These and other findings spurred researchers to identify the mechanisms linking physical punishment and child aggression.

By the 1990s, it was recognized that the method by which causality is typically shown in scientific studies-randomized controlled trials (RCTs)-have very limited application for studying the physical punishment of children. Although RCTs can be used to study the effect of reducing physical punishment, they cannot be used to study the effect of imposing such punishment because it would be unethical to assign children to a group receiving painful treatment when research already suggests that such pain poses potential harm not outweighed by potential benefit. The few existing RCTs showed that physical punishment was no more effective than other methods in eliciting compliance. In one such study, an average of eight spankings in a single session was needed to elicit compliance, and there was 'no support for the necessity of the physical punishment.' $^{\text {,10) }}$

To address the causality question within ethical bounds, researchers designed prospective studies of children who had equivalent levels of aggression or antisocial behavior at time 1. In addition, increasingly sophisticated statistical modeling techniques were applied to correlational studies to aid understanding of their results. These studies changed the way in which physical punishment would be researched over the subsequent decade and redrew the landscape of the debate.

\section{THE NEW MILLENIUM: ADDRESSING CAUSATION AND BROADENING FOCUS}

One of the first major prospective studies ( $\mathrm{n}=807)$ controlled for initial level of child antisocial behavior, child sex, family socioeconomic status, and levels of emotional support and cognitive stimulation in the home. ${ }^{11)}$ Even with these controls, physical punishment between the ages of six and nine years predicted higher levels of child antisocial behavior two years later. Subsequent prospective studies yielded similar results, whether they controlled for parental age, child age, race and family structure; ${ }^{12)}$ poverty, child age, emotional support, cognitive stimulation, sex, race and the interactions among these variables; ${ }^{13)}$ or other factors. ${ }^{14-17)}$ These studies provide the strongest evidence available that physical punishment is a risk factor for child aggression and antisocial behavior.

A landmark meta-analysis published in $2002^{18)}$ showed that of the 27 studies on physical punishment and child aggression conducted up to that time (that met the criteria of the meta-analysis), all found a significant positive relationship, regardless of the size of the sample, location of study, ages of the children or any other variable. Virtually all adequately designed studies conducted since that meta-analysis have found the same relationship. ${ }^{19-24)}$

In a RCT of an intervention designed to reduce difficult child behaviors, ${ }^{25)}$ parents in more than 500 families were trained to decrease their use of physical punishment. The significant parallel decline seen in the difficult behaviors of children in the treatment group was largely explained by the parents' reduction of their use of physical punishment. Together, results consistently suggest that physical punishment has a direct causal effect on externalizing behavior, whether through a reflexive response to pain, modeling or coercive family processes.

By 2000, research on physical punishment had expanded beyond its effect on child aggression. Studies were uncovering associations between physical punishment and mental health, physical injury, parent-child relationships and family violence in adulthood. One of the first such studies ${ }^{26)}$ linked slapping and spanking in childhood with psychiatric disorders in adulthood in a large Canadian general population sample, and its findings have been supported by an ever-growing number of studies. Physical punishment is associated with a range of mental health problems in children, youth and adults, including depression, anxiety, feelings of hopelessness, use of drugs and alcohol, unhappiness and general psychological maladjustment. ${ }^{24,27-31)}$ These relationships may be mediated by disruptions in parent-child attachment resulting from pain inflicted by a caregiver ${ }^{32,33)}$ by increased levels of cortisol, ${ }^{34)}$ or by chemical disruption of the brain's mechanism for regulating stress. ${ }^{35)}$ Researchers are also finding that physical punishment is linked to slower cognitive development and receptive vocabulary, and poorer academic achievement. ${ }^{36,37)}$ These findings come from large longitudinal studies that control for a wide range of potential confounders. ${ }^{38)}$ Intriguing results are now emerging from neuroimaging studies that suggest physical punishment may reduce the volume of grey matter in the prefrontal cortex ${ }^{39)}$ and may cause alter- 
ations in the dopaminergic regions associated with vulnerability to drug and alcohol abuse. ${ }^{40)}$ Parents' verbal hostility, which typically accompanies physical punishment, toward preschool children predicts smaller hippocampal volume several years later. ${ }^{41)}$ Indeed, more than 180 studies have found associations between childhood maltreatment and changes in the structure, function or architecture of the brain. ${ }^{42)}$ Other studies are examining the role of genetics in physical punishment's observed impacts. For example, in a large longitudinal study, the effect of physical punishment was amplified among boys with greater genetic risk for antisocial behavior. ${ }^{43)}$

All these findings are consistent with the rapidly growing body of literature on the impact of adverse childhood experiences on neurological, cognitive, emotional and social development, and on physical health. ${ }^{44)}$ Although some studies have found no relationship between physical punishment and negative outcomes, ${ }^{38)}$ and others have found the relationship to be moderated by other factors, ${ }^{12)}$ no study has found physical punishment to have a long-term positive effect, and the vast majority have found negative effects. A recent metaanalysis of 75 studies focused exclusively on spanking, one of the most common forms of physical punishment, yielded 79 unique significant effect sizes. ${ }^{31)}$ Of these, $99 \%$ indicated associations between spanking and negative child outcomes including externalizing and internalizing behavior problems, child mental health problems, child aggression and antisocial behavior, low moral internalization, negative parent-child relationships, and low self-esteem. The magnitude of the effect sizes did not vary across studies' design characteristics.

Another major change in the landscape was precipitated by research that questioned the traditional punishment vs. abuse dichotomy. While research demonstrating that most physical abuse actually is physical punishment-in intent, form and effect-began to accumulate in the 1970s, studies of child maltreatment have since elucidated this finding. For example, the first cycle of the Canadian Incidence Study of Reported Child Abuse and Neglect ${ }^{45}$ [Canadian Incidence Study (CIS)-1998], revealed that $75 \%$ of substantiated child physical abuse occurred during episodes of physical punishment. This finding was replicated in the second cycle of the study (CIS-2003). ${ }^{46)}$ Another large Canadian study ${ }^{47)}$ found that children who were spanked by their parents were seven times more likely to be severely assaulted (e.g., punched or kicked) by their parents than children who were not spanked. In an American study, ${ }^{48)}$ infants in their first year of life who had been spanked by their parents in the previous month were more than twice as likely to suffer an injury requiring medical attention than infants who had not been spanked. Another American study found that every time a child is spanked, their odds of being abused (e.g., kicked, punched, burned) increased by $3 \%$; if they were hit with objects, the odds of abuse increased by $9 \% .{ }^{49)}$ Studies of the dynamics of child physical abuse have shed light on this escalation process that involves parental attributions for conflict to child willfulness $^{50)}$ and/or rejection, ${ }^{51)}$ coercive family dynamics, ${ }^{9)}$ and conditioned emotional responses. ${ }^{52}$

Empirical evidence of the falsity of the punishment vs. abuse dichotomy is accumulating. A meta-analysis of seven studies reporting effect sizes for both 'spanking' and 'physical abuse' revealed that the relationships between spanking and negative child outcomes were similar in size to those found between more severe physical abuse and the same child outcomes. ${ }^{31)}$ Physical abuse is a well-established toxic stressor. ${ }^{53)}$ Given the consistency with which physical punishment has been found to predict negative developmental outcomes, it has been argued that even 'normative' spanking should be considered a source of toxic stress. ${ }^{54}$

The mounting and persuasive evidence linking negative developmental outcomes with physical punishment has contributed to a global shift in perceptions of the practice. In Canada, for example, 583 organizations have to date endorsed the Joint Statement on Physical Punishment of Children and Youth, ${ }^{55)}$ including the Canadian Academy of Child and Adolescent Psychiatry, Canadian Medical Association and Canadian Paediatric Society. In other countries, legislative reforms have been instituted to better protect children. ${ }^{56)}$ Professional organizations that support the elimination and prohibition of physical punishment include the International Association for Adolescent Health, International Pediatric Association, International Society for Social Pediatrics and Child Health, and International Society for the Prevention of Child Abuse and Neglect. Accompanying these changes has been a growing emphasis on developing models of positive discipline that rely on nonviolent and effective conflict resolution. ${ }^{57)}$

\section{THE FUTURE: PROMOTING POSITIVE DISCIPLINE}

An ever-growing body of research is demonstrating the primary role of warm, supportive relationships in optimizing children's development. ${ }^{58-61)}$ There is considerable evidence that children's successful passage through development is fostered by 'positive discipline'-that is, parenting that models non-aggression and self-regulation, scaffolds learning, mediates children's interpretations of challenging events, and coaches children in managing stress and repairing mistakes. ${ }^{62)}$

It is now 25 years since the Republic of Korea ratified the CRC, which calls for the elimination of all forms of violence against children, including physical punishment. ${ }^{63)}$ In that time, the global debate has moved beyond academic discus- 
sions of outcomes and causality to discussions of life span outcomes, societal impact, ethics, law and human rights. This new context for examining physical punishment has propelled legal, policy and attitudinal changes worldwide. ${ }^{56}$ An increasing number of countries are abolishing physical punishment to better protect their children and to shift parents' focus from punishment to guidance and positive discipline. Evidence is emerging that the combination of law reform and public education is more effective than either strategy alone in changing parental attitudes and behaviors. ${ }^{64)}$

The Republic of Korea has not yet developed a systematic approach to child abuse prevention. ${ }^{24)}$ Physicians in general, and psychiatrists in particular, have a primary role to play in changing this situation. They hold responsibility for translating health research evidence into guidance for parents and children, and they are also credible and influential voices for advancing public education and policy regarding population health. For example, physicians can educate parents regarding the findings of research on physical punishment, inform them about typical child development, help them to reduce angry and punitive responses to normative child behaviors, and provide them with resources on positive discipline ${ }^{55)} \mathrm{Phy}-$ sicians can refer parents to public health programs, parent resource centres, positive parenting programs and other clinical professionals for further support. In addition, physicians can engage with other professionals to send clear, unambiguous messages about physical punishment on a population level. Physicians also can urge governments to prohibit physical punishment as an important statement of child protection and respect for children's rights, but also as a primary prevention strategy. Law can either reinforce public health messaging or undermine it.

The research evidence and human rights imperatives are clear and compelling-physical punishment of children plays no useful role in their upbringing and poses only risks to their development. Parents should be strongly encouraged to develop alternative and positive approaches to discipline.

\section{Conflicts of Interest}

The authors have no financial conflicts of interest.

\section{REFERENCES}

1) Global initiative to end all corporal punishment of children. [cited 2016 Sep 25]. Available from: www.endcorporalpunishment.org.

2) Straus MA. Ordinary violence, child abuse, and wife-beating: what do they have in common? In: Finkelhor D, Gelles RJ, Hotaling GT, Straus MA, editors. The dark side of families: current family violence research. Beverly Hills, CA: Sage;1983. p.213-234.

3) Travillion K, Snyder J. The role of maternal discipline and involvement in peer rejection and neglect. J Appl Dev Psychol 1993;14:3757.

4) Straus MA. Discipline and deviance: physical punishment of children and violence and other crime in adulthood. Social Problems
1991;38:133-154.

5) Larzelere R. Moderate spanking: model or deterrent of children's aggression in the family? J Fam Violence 1986;1:27-36.

6) Straus MA. Some social antecedents of physical punishment: a linkage theory interpretation. J Marriage Fam 1971;33:658-663.

7) Azrin NH, Hake DF, Hutchinson RR. Elicitation of aggression by a physical blow. J Exp Anal Behav 1965;8:55-57.

8) Fairchild L, Erwin WM. Physical punishment by parent figures as a model of aggressive behavior in children. J Genet Psychol 1977;130: 279-284.

9) Forgatch MS. The clinical science vortex: a developing theory of antisocial behavior. In: Pepler DJ, Rubin KH, editors. The development and treatment of childhood aggression. Hillsdale, MJ: Erlbaum;1991. p.291-315.

10) Day DE, Roberts MW. An analysis of the physical punishment component of a parent training program. J Abnorm Child Psychol 1983; 11:141-152.

11) Straus MA, Sugarman DB, Giles-Sims J. Spanking by parents and subsequent antisocial behavior of children. Arch Pediatr Adolesc Med 1997;151:761-767.

12) Gunnoe ML, Mariner CL. Toward a developmental-contextual model of the effects of parental spanking on children's aggression. Arch Pediatr Adolesc Med 1997;151:768-775.

13) Grogan-Kaylor A. Corporal punishment and the growth trajectory of children's antisocial behavior. Child Maltreat 2005;10:283-292.

14) Mulvaney MK, Mebert CJ. Parental corporal punishment predicts behavior problems in early childhood. J Fam Psychol 2007;21:389397.

15) Slade EP, Wissow LS. Spanking in early childhood and later behavior problems: a prospective study of infants and young toddlers. Pediatrics 2004;113:1321-1330.

16) Taylor CA, Manganello JA, Lee SJ, Rice JC. Mothers' spanking of 3 -year-old children and subsequent risk of children's aggressive behavior. Pediatrics 2010;125:e1057-e1065.

17) Grogan-Kaylor A. The effect of corporal punishment on antisocial behavior in children. Soc Work Res 2004;28:153-162.

18) Gershoff ET. Corporal punishment by parents and associated child behaviors and experiences: a meta-analytic and theoretical review. Psychol Bull 2002;128:539-579.

19) Aucoin KJ, Frick PJ, Bodin SD. Corporal punishment and child adjustment. J Appl Dev Psychol 2006;27:527-541.

20) Fine SE, Trentacosta CJ, Izard CE, Mostow AJ, Campbell JL. Anger perception, caregivers' use of physical discipline, and aggression in children at risk. Soc Dev 2004;13:213-228.

21) Lansford JE, Chang L, Dodge KA, Malone PS, Oburu P, Palmérus $\mathrm{K}$, et al. Physical discipline and children's adjustment: cultural normativeness as a moderator. Child Dev 2005;76:1234-1246.

22) Ohene SA, Ireland M, McNeely C, Borowsky IW. Parental expectations, physical punishment, and violence among adolescents who score positive on a psychosocial screening test in primary care. Pediatrics 2006;117:441-447.

23) Pagani L, Tremblay R, Nagin D, Zoccolillo M, Vitaro F, McDuff P. Risk factor models for adolescent verbal and physical aggression toward mothers. Int J Behav Dev 2004;28:528-537.

24) You S, Lim SA. Development pathways from abusive parenting to delinquency: the mediating role of depression and aggression. Child Abuse Negl 2015;46:152-162.

25) Beauchaine TP, Webster-Stratton C, Reid MJ. Mediators, moderators, and predictors of 1-year outcomes among children treated for early-onset conduct problems: a latent growth curve analysis. J Consult Clin Psychol 2005;73:371-388.

26) MacMillan HL, Boyle MH, Wong MY, Duku EK, Fleming JE, Walsh CA. Slapping and spanking in childhood and its association with lifetime prevalence of psychiatric disorders in a general population sample. CMAJ 1999;161:805-809. 
27) Afifi TO, Brownridge DA, Cox BJ, Sareen J. Physical punishment, childhood abuse and psychiatric disorders. Child Abuse Negl 2006; 30:1093-1103.

28) Turner HA, Muller PA. Long-term effects of child corporal punishment on depressive symptoms in young adults potential moderators and mediators. J Fam Issues 2004;25:761-782.

29) Javo C, Rønning JA, Heyerdahl S, Rudmin FW. Parenting correlates of child behavior problems in a multiethnic community sample of preschool children in northern Norway. Eur Child Adolesc Psychiatry 2004;13:8-18.

30) Rodriguez CM. Parental discipline and abuse potential affects on child depression, anxiety, and attributions. J Marriage Fam 2003;65: 809-817.

31) Gershoff ET, Grogan-Kaylor A. Spanking and child outcomes: old controversies and new meta-analyses. J Fam Psychol 2016;30:453469.

32) Coyl DD, Roggman LA, Newland LA. Stress, maternal depression, and negative mother-infant interactions in relation to infant attachment. Infant Ment Health J 2002;23:145-163.

33) Palmer EJ, Hollin CR. Sociomoral reasoning, perceptions of parenting and self-reported delinquency in adolescents. Appl Cogn Psychol 2001;15:85-100.

34) Bugental DB, Martorell GA, Barraza V. The hormonal costs of subtle forms of infant maltreatment. Horm Behav 2003;43:237-244.

35) McGowan PO, Sasaki A, D'Alessio AC, Dymov S, Labonté B, Szyf $M$, et al. Epigenetic regulation of the glucocorticoid receptor in human brain associates with childhood abuse. Nat Neurosci 2009;12: 342-348.

36) Straus MA, Paschall MJ. Corporal punishment by mothers and development of children's cognitive ability: a longitudinal study of two nationally representative age cohorts. J Aggress Maltreat Trauma 2009;18:459-483

37) MacKenzie MJ, Nicklas E, Waldfogel J, Brooks-Gunn J. Corporal punishment and child behavioral and cognitive outcomes through 5 years-of-age: evidence from a contemporary urban birth cohort study. Infant Child Dev 2012;21:3-33.

38) Bradley RH, Convyn RF, Burchinal M, McAdoo HP, Coll CG. The home environments of children in the United States part II: relations with behavioral development through age thirteen. Child Dev 2001; 72:1868-1886.

39) Tomoda A, Suzuki H, Rabi K, Sheu YS, Polcari A, Teicher MH. Reduced prefrontal cortical gray matter volume in young adults exposed to harsh corporal punishment. Neuroimage 2009;47 Suppl 2: T66-T71.

40) Sheu YS, Polcari A, Anderson CM, Teicher MH. Harsh corporal punishment is associated with increased $\mathrm{T} 2$ relaxation time in dopamine-rich regions. Neuroimage 2010;53:412-419.

41) Luby J, Belden A, Botteron K, Marrus N, Harms MP, Babb C, et al. The effects of poverty on childhood brain development: the mediating effect of caregiving and stressful life events. JAMA Pediatr 2013;167:1135-1142.

42) Teicher MH, Samson JA, Anderson CM, Ohashi K. The effects of childhood maltreatment on brain structure, function and connectivity. Nat Rev Neurosci 2016;17:652-666.

43) Boutwell BB, Franklin CA, Barnes JC, Beaver KM. Physical punishment and childhood aggression: the role of gender and gene-environment interplay. Aggress Behav 2011;37:559-568.

44) Anda RF, Felitti VJ, Bremner JD, Walker JD, Whitfield C, Perry $\mathrm{BD}$, et al. The enduring effects of abuse and related adverse experiences in childhood. A convergence of evidence from neurobiology and epidemiology. Eur Arch Psychiatry Clin Neurosci 2006; 256:174-186.

45) Trocmé N, MacLaurin B, Fallon B, Daciuk J, Billingsley D, Tourigny $\mathbf{M}$, et al. Canadian incidence study of reported child abuse and neglect: final report. Ottawa: Minister of Public Works and Government Services Canada;2001.

46) Trocmé N, Fallon B, MacLaurin B, Daciuk J, Felstiner C, Black T, et al. Canadian incidence study of reported child abuse and neglect-2003: major findings. Ottawa: Minister of Public Works and Government Services Canada;2005.

47) Clément ME, Bouchard C, Jetté M, Laferrière S. La violence familiale dans la vie des enfants du Québec. Québec: Institut de la statistique du Québec; 2000 .

48) Crandall M, Chiu B, Sheehan K. Injury in the first year of life: risk factors and solutions for high-risk families. J Surg Res 2006;133:710.

49) Zolotor AJ, Theodore AD, Chang JJ, Berkoff MC, Runyan DK. Speak softly--and forget the stick. Corporal punishment and child physical abuse. Am J Prev Med 2008;35:364-369.

50) Dietrich D, Berkowitz L, Kadushin A, McGloin J. Some factors influencing abusers' justification of their child abuse. Child Abuse Negl 1990;14:337-345.

51) Korbin JE. Incarcerated mothers' perceptions and interpretations of their fatally maltreated children. Child Abuse Negl 1987;11:397407.

52) Wolfe DA. Child abuse: implications for child development and psychopathology. Newbury Park, CA: Sage;1987.

53) Jaffee SR, Christian CW. The biological embedding of child abuse and neglect implications for policy and practice. Soc Policy Rep 2014;28:3-19.

54) Gershoff ET. Should parents' physical punishment of children be considered a source of toxic stress that affects brain development? Fam Relat 2016;65;151-162.

55) Durrant JE, Ensom R, Coalition on Physical Punishment of Children and Youth. Joint statement on physical punishment of children and youth. Ottawa, ON: The Coaltion;2004.

56) Durrant JE, Smith AB. Global pathways to abolishing physical punishment: realizing children's rights. New York: Routledge;2011.

57) Durrant JE. Positive discipline in everyday parenting. Stockholm: Save the Children Sweden;2013.

58) Goleman D. Social intelligence: the new science of social relationships. New York: Bantam Books; 2006.

59) National Scientific Council on the Developing Child. Children's emotional development is built into the architecture of their brains 2004. Working Paper No. 2. [cited 2016 Sep 25]. Available from: http://developingchild.net.

60) Oberle E, Schonert-Reichl KA, Guhn M, Zumbo BD, Hertzman C. The role of supportive adults in promoting positive development in middle childhood: a population-based study. Can J Sch Psychol 2014:29:296-316.

61) Pepler D, Craig W, Haner D. Healthy development depends on healthy relationships. Ottawa: PREVNet Healthy Relationships Project, Division of Childhood and Adolescence, Centre for Health Promotion, Public Health Agency of Canada;2012.

62) Holden GW. Childrearing and developmental trajectories: positive pathways, off-ramps, and dynamic processes. Child Dev Perspect 2010;4:197-204.

63) UN Committee on the Rights of the Child. General comment No. 8 (2006): The Right of the Child to Protection from Corporal Punishment and Other Cruel or Degrading Forms of Punishment (Arts. 19; 28, Para. 2; and 37, inter alia), 2 March 2007, CRC/C/GC/8. [cited 2016 Sep 25]. Available from: http://www.refworld.org/docid/ $460 \mathrm{bc} 7772$. html.

64) Bussman Kai-D, Erthal C, Schroth A. Effects of banning corporal punishment in Europe: a five-nation comparison. In: Durrant JE, Smith AB, editors. Global pathways to abolishing physical punishment: realizing children's rights. New York: Routledge;2011. p.299322. 